DOI: $10.7256 / 1812-8696.2013 .04 .17$

\title{
\&! ПОББИЗМ
}

\section{А.А. Гришанов}

\section{РОЛЬ ЗАИНТЕРЕСОВАННЫХ ГРУПП В ПРОЦЕССЕ ПОСТРОЕНИЯ БЛИЖНЕВОСТОЧНОЙ ПОЛИТИКИ США}

\begin{abstract}
Аннотация: Одним из основополагающих механизмов американского внешнеполитического процесса являются заинтересованные группы. Их роль в принятии решений по вопросам позииионирования страны на Ближнем Востоке, построения диалога с Израилем и арабским миром, участия в военных операциях, на протяжении долгих лет находилась в иентре экспертной дискуссии. В статье подробно рассматриваются эволюиия структур этнического лобби, конкурениия произраильских и проарабских организаџий, возникновение объединений идеологического характера и их воздействие на принятие политических решений касательно использования американской военной силь в регионе. Дана характеристика широкому спектру организачий и персоналий, задействованных в соответствующей лоббистской деятельности.
\end{abstract}

Ключевые слова: Политология, Лоббизм, Группь, США, Ирак, Конгресс, Сенат, плюрализм, дебатьи, Израиль

$\Pi$ о мере роста торгового оборота США с зарубежными партнерами, расширения военного присутствия страны за рубежом, увеличения дипломатической активности, развивались и становились все более деятельными заинтересованные группы $^{1}$, часто также именуемые «группами интересов» или, с некоторыми оговорками, группами давления, нацеленные на влияние на внешнюю политику страны. Сегодня они играют ключевую роль в организации публичных дебатов по вопросам ратификации международных договоров; начала и окончания военных действий американских ВС за рубежом; введения санкций в отношении тех или иных государств; или, если говорить шире, относительно выработки всего курса США на мировой арене. Такие группы превратились в неотъемлемый атрибут процесса определения роли США в урегулировании ближневосточного конфликта, выстраивания отношений с ЕС и другими

\footnotetext{
${ }^{1}$ Понятие «заинтересованные группы», синонимичное понятию «группа интересов», в частности употребляли проф. К.С.Гаджиев (Гаджсиев К.С. Политическая наука. М.: Международные отношения, 1994. 400 с.) и д.п.н. Н.Г.Зяблюк (Зяблюк Н.Г. Политический плюрализм: контуры американской модели // «США-Канада: экономика, политика, культуpa» 1999, № 5. C. 3-18)
}

мировыми державами, а также поддержания диалога в сфере разоружения. В связи с этим в центре повестки дня особое место заняло и российско-американское сотрудничество, начавшееся в годы разрядки международной напряженности и продолжающееся по сей день. По ряду причин, включая кардинальное изменение расстановки сил на Большом Ближнем Востоке, проведение серии военных кампаний, активизацию террористических объединений, наконец, события «Арабской весны», в последние годы в центре внимания находился именно этот регион - многочисленные и влиятельные группы, ассоциации, комитеты и пр. выступали (и продолжают выступать) активными сторонниками вовлечения страны в региональные конфликты в качестве важной регулирующей силы. Сегодня, когда внимание всего мира вновь приковано к этому взрывоопасному вопросу, экспертное сообщество возвращается к давно поставленным вопросам: какие организации, группы и личности направляют политику США в регионе? Кто продвигает идеи осуществления американских военных акций на Большом Ближнем Востоке? Насколько сбалансировано представлены в вашингтонском политическом истеблишменте, в первую очередь, в Конгрессе, сторонники различных вариантов развития события? В рамках одной 


\section{Политика и общество 4 (100) • 2013}

из попыток дать ответ на эти и другие вопросы, и обозначены соответствующие примеры, рассматривающиеся в данной статье.

Наиболее ярким из них, в силу своей высокой организованности и чрезвычайно сильного влияния, являются произраильские объединения.

Влиятельные еврейские организации начали формироваться в США в первые десятилетия двадцатого века. В 1906 году был создан Американский еврейский комитет, через некоторое время произошло учреждение сионистских групп, самой заметной из которых стала Сионистская организация Америки ${ }^{2}$. Их основной задачей стало отстаивание интересов еврейского населения, ущемлявшегося в различных государствах мира, и продвижение тезиса о необходимости создания еврейского государства в Палестине. Прорывом в деле консолидации американских евреев можно считать созыв Конференции президентов главных американских еврейских организаций, произошедший вскоре после образования Израиля. Важнейшей вехой, безусловно, явилось появление Американо-Израильского комитета по общественным делам. Не являясь комитетом политического действия, комитет не осуществляет взносы в избирательные фонды, что не мешает ему оставаться самой влиятельной и авторитетной еврейской организацией страны.

Однако подобную деятельность практикуют другие произраильские организации, включая Центр ответственной политики, Национальный комитет действия и Союз женщин за Израиль. В течение каждого избирательного цикла эти структуры выделяют различным кандидатам от 2 до 3,5 миллионов долларов.

Наиболее влиятельной произраильской группой является Американо-Израильский комитет по общественным делам ${ }^{3}$. Его основатель И.Л. «Си» Кенен в 1951 году возглавлял Американский сионистский совет, зарегистрированный в качестве группы иностранного лобби. Кенен полагался на персональные контакты с законодателями, нежели на общественные компании или мобилизацию масс. До середины 1960-х годов масштабы деятельности еврейского лобби в целом оставались незначительными. Однако после победы Израиля в Шестидневной войне и

\footnotetext{
${ }^{2}$ Zionist Organisation of America, далее по тексту используется англоязычная аббревиатура ZOA

${ }^{3}$ The American Israel Public Affairs Committee, в русскоязычной литературе обычно используется англоязычная аббревиатура AIPAC (либо ЭЙПАК)
}

Войне Судного дня рост американской финансовой и военной помощи этой стране привел к резкой активизации организаций вроде AIPAC, добивавшихся увеличения средств, выделяемых Вашингтоном. В это же время происходит смена руководства данной группы, место Кенана занимают Моррис Амитэй, которого позднее сменил Том Дайм. Под их началом происходит значительное расширение масштабов деятельности AIPAC: штат организации превышает 150 человек, а годовой бюджет составляет около 4060 миллионов долларов, основу которых составляют частные пожертвования (в 1973 году эта цифра составляла 300.000 долларов).

Джон Мершаймер, автор книги «Израильское лобби и внешняя политика США», прямо отмечал: «Успех AIPAC предопределен его умением отдавать должное законодателям-сторонникам и наказывать оппонентов. АIPAC создает гарантии получения первыми финансовой помощи от множества произраильских КПД. В то же время, политики, враждебно настроенные по отношению к Израилю, уверены, что пожертвования будут направлены их конкурентам».

После принятия поправки Джексона-Вэника израильское лобби четко ощутило свою силу. В 70-е годы по инициативе заинтересованных групп было проведено несколько законопроектов, запрещавших выполнение американским компаниями условий арабского бойкота Израиля. Формально бойкот был объявлен ЛАГ еще до создания еврейского государства, в 1945 году, и призывал компании соответствующих государств отказаться от торговли с Израилем. Более того, страны - члены Лиги угрожали прервать все торгово-экономические отношения с государствами, которые станут поставлять Израилю товары и сырье. Спустя три года представители организации заявили, что бойкот распространяется не только на компании, торгующие с израильтянами, но также на третьи фирмы, так или иначе сотрудничающие с этими компаниями; одновременно было сформировано специальное бюро по бойкотированию Израиля.

В 1955 году США и Великобритания разработали план с целью окончания арабского бойкота. На первом этапе реализации плана арабы должны были снять бойкот, на втором Израилю в обмен на это предстояло демаркировать границы с Египтом и Иорданией; однако план так и не был реализован, поскольку ни одна из сторон не приняла его. В результате, возникла двусмысленная ситуация: при том, что правительство США поддерживало Тель-Авив, крупнейшие 
DOI: $10.7256 / 1812-8696.2013 .04 .17$

Лоббизм

налогоплательщики были вынуждены выполнять условия антиизраильских сил. В 1975 году сенатор от штата Нью-Йорк Джонатан Бингэм предложил законопроект, призванный урегулировать проблему. Последовавшие дебаты привели к выявлению серьезных противоречий в позициях лобби с одной стороны, и администрации Форда (а также крупных бизнесструктур) с другой. Инвестиции в американо-арабский бизнес к этому времени составляли 4,5 миллиарда долларов, что предопределило конфликт интересов. В первой половине 1976 года состоялись дискуссии лоббистов и предпринимателей (объединенных в так называемый «Круглый стол по вопросам бизнеса»). В результате, в итоговом тексте закона прослеживался компромисс, предусматривавший исключения, например, для нефтяных компаний.

Вопреки распространенному мнению, далеко не во всех случаях еврейские группы выступают единым фронтом. Например, в 2006 году менее известные организации Израильский политический форум, Американцы за мир сейчас, Еврейский голос за мир и Брит Зедек Вшалом открыто оппонировали поддержанной AIPAC резолюции Конгресса, накладывавшие еще более жесткие ограничения на помощь палестинцам, нежели те, что предлагались правительством Израиля.

Попытки создать альтернативу AIPAC предпринимались и ранее. В 1973 году была создана организация Брейра, выступившая с прогрессивными для своего времени предложениями о выводе израильских войск с оккупированных территорий и мирном урегулировании палестинского вопроса. Деятельность и заявления лидеров Брейры сразу же подверглись ожесточенной критике со стороны печатных органов AIPAC, Харасса и ZOA. В результате последовавшего давления данная группа прекратила свою деятельность через 5 лет. Похожие прецеденты возникают и в наше время. В 2006 году нападкам со стороны крупнейших еврейских групп подвергся Союз прогрессивных сионистов, выступавший с критикой действий израильской армии на оккупированных территориях. ZOA открыто призвала к исключению Союза из влиятельной коалиции «Израиль на Кампусе» (сконцентрирована на предотвращении антиизраильской активности в университетский кампусах в США).

С началом переговорного процесса в Осло, как в Израиле, так и в США частично усилились правые и даже крайне праве настроения. В 1994 году ZOA успешно пролоббировала поправку к биллю об иностранной помощи, накладывавшую дополнительные ограничения на помощь, оказываемую США Палестинской автономии, несмотря на сопротивление как администрации Клинтона, так и правительства Рабина. Конференция президентов, в отличие от ряда ее участников, не поддержала переговоры, а AIPAC выступила спонсором Акта о посольстве в Иерусалиме, призывавшем США переместить в этот город диппредставительство из Тель-Авива. Как известно, оккупация Восточного Иерусалима в июне 1967 года и последующая аннексия Старого города и его окрестностей Израилем не признаны международным сообществом; по мнению Вашингтона, статус Иерусалима должен определяться соглашением, достигнутым в результате израильско-палестинских переговоров.

Разумеется, кроме еврейских организаций, влияние на ближневосточную политику США и соответствующие законодательные решения осуществляют и структуры, относимые к арабскому лобби. Вплоть до 1980-х годов американские арабы предпочитали не вовлекаться в традиционную лоббистскую деятельность, сосредоточившись на расширении неформального влияния на элиты страны. Однако зачатки институционализации проарабских заинтересованных групп можно наблюдать еще в довоенное время. Именно тогда возникает одна из первых подобных структур, Национальная арабская лига, отстаивавшая интересы палестинцев. В аналогичном русле действовало сообщество «Американские друзья арабов». В 40-е годы возникают Лига американо-арабского комитета за демократию, Институт по делам американских арабов и ряд других групп. Одновременно на деньги иракского правительства реализовывается амбициозный проект так называемого Арабского офиса. Число аналогичных структур продолжает поступательно расти к 1960-м годам, однако по степени своего влияния и возможностей они серьезно уступали еврейским объединениям. Так, единственной организацией, зарегистрированной в это время в качестве лоббистской оставался Гражданский комитет по американской политике на Ближнем Востоке, не оказавшей значимого воздействия на политику страны. Более ощутимым оказался эффект от работы созданной в 1972 году Национальной ассоциации американских арабов (НААА). Спустя год спустя после своего возникновения, ассоциация в ряду нескольких других групп выступала за введение эмбарго на поставки оружия в Израиль в ходе Войны судного дня. Позднее, НААА добилась поддержки со стороны 40 сенаторов при обсуждении поправки, затрагивающей использование Израилем американских 


\section{Политика и общество 4 (100) • 2013}

военных технологий. В 1981 году США выразили желание продать Саудовской Аравии системы бортовых предупреждений и команд, способных значительно усилить саудовские ВВС. Так как де-юре королевство все еще находилось в состоянии войны с Израилем, последний выступил против подобного решения. Несмотря на очевидные финансовые выгоды сделки и поддержку со стороны Белого дома, Палата представителей под влиянием еврейских организаций проголосовала против в соотношении 3 к 1. Аналогичную позицию занял и Сенат.

Слабость арабских организаций в наибольшей степени ощущалась в ходе военных конфликтов на Ближнем Востоке. Несмотря на сопротивление арабских заинтересованных групп, в 2009 году лишь 5 конгрессменов не поддержали резолюцию с одобрением действий Израиля в ходе операции «Литой свинец» в Секторе Газа. При этом реакция США контрастировала с позицией международной общественности, которая была скорее отрицательной. Так, на протяжении операции мировое сообщество неоднократно призывало Израиль прекратить бомбардировки Газы. В дальнейшем, только 36 членов Палаты представителей отказались осудить доклад Совета по правам человека ООН, в котором действия Тель-Авива были подвергнуты жесткой критике.

Для сравнения приведу другой пример. В 2006 году еврейские заинтересованные группы также оказались в центре внимания в связи с событиями вокруг Ливана. Израиль начал крупную военную операцию против базирующейся в Ливане вооруженной группировки мусульман-шиитов “Хезболла” после того как она похитила двух израильских солдат; непропорционально жесткие действия ЦАХАЛ встретили серьезную обеспокоенность мирового сообщества. Однако в США события развивались в соответствии с особой логикой. Так, AIPAC заблокировал попытку влиятельных членов Конгресса от обеих партий под руководством Нэнси Пелоси и Джона Уорнера дополнить текст посвященной конфликту резолюции Палаты представителей призывом к обеим сторонам «защищать жизни и инфраструктуру мирного населения». В дальнейшем, еврейское лобби оказало давление на конгрессмена Кристофера Ван Холена, написавшего критическое письмо госсекретарю с резкими оценками израильской политики в Ливане, вынудив его выступить с оправдательными заявлениями.

В конце 2001 года 89 сенаторов при активном участии AIPAC направили коллективное письмо прези- денту с требованием продолжить оказание поддержки действиям Израиля в Палестине. В 2002 году в ходе операции ЦАХАЛ «Оборонительный щит» на Западном берегу реки Иордан, встретившей негативную реакцию в Белом доме, обе палаты Конгресса проголосовали за резолюции, в которых также выражалась безоговорочная поддержка действиям правительства Ариэля Шарона.

В 2002-2003 гг. еврейские лоббистские группы отстаивали необходимость, принятия законопроекта, содержавшего угрозу введения санкций против Сирии в случае продолжения поддержки террористических групп и разработки ОМП. Инициатор законопроекта конгрессмен Энгель даже совершил визит в Израиль, встретившись с Ариэлем Шароном, выразившим обеспокоенность недостаточно активной позицией администрации Белого дома по сирийскому вопросу. В результате оказывавшегося давления, законопроект был принят обеими палатами и подписан скептически настроенным по отношению к нему Бушем-мл.

AIPAC эффективно проявил себя и в общественной кампании против Ирана. В 2007 году ряд конгрессменов предприняли попытку законодательно обязать администрацию предварительно согласовать с обеими палатами военные действия против этой страны в случае решения о проведении соответствующей операции. По мнению членов Палаты представителей Майкла Капуано и Дениса Кусинича, именно действия AIPAC привели к тому, что в конечном счете соответствующее положение не было выставлено на голосование. Руководители AIPAC Ховард Кор и Стивен Розен также признавали, что комитет активно лоббировал Конгресс с целью обеспечения законодательной поддержки военных действий в Ираке.

Для отстаивания интересов Израиля в Конгрессе используются различные инструменты. Например, в 2007 году на слушания подкомитета по Ближнему Востоку и Центральной Азии Палаты представителей были приглашены только активные сторонники Тель-Авива - Дэвид Маковский, Мартин Индик и Дэниэл Пайпс, в результате чего заседание носило крайне несбалансированный характер. Многие члены и ведущие сотрудники аппарата Конгресса занимают одностороннюю позицию по обсуждаемым вопросам, поддерживая тесную связь с еврейскими заинтересованными группами. Центральной составляющей лоббистских усилий того же AIPAC можно назвать возможность оперировать значительными финансовыми средствами, находящимися в распоряжении членов 
DOI: $10.7256 / 1812-8696.2013 .04 .17$

Лоббизм

руководства организации, а также способность успешно организовать встречи с потенциальными донорами и комитетами политического действия. Собственно, последние в огромной степени подконтрольны сотрудникам и руководителям АIPAC. Множество членов Конгресса обязаны еврейскому лобби победой на выборах. В случае же недостаточно проявлявшейся произраильской позиции, на соответствующих законодателей традиционно обрушивался шквал критики, в то время как их оппоненты начинали получать дополнительное финансирование, зачастую предопределявшее исход политических схваток. По мнению бывшего президента Картера, призыв к занятию сбалансированной позиции по вопросу арабо-израильского конфликта зачастую равносилен «политическому самоубийству» ${ }^{4}$.

Ежегодно AIPAC приглашает представителей вашингтонского истеблишмента, включая многих сенаторов и членов Палаты представителей на свою ежегодную конференцию, которая наиболее красноречиво отражает масштаб данной организации с политической элитой страны. AIPAC на регулярной основе привлекается к ежедневной работе в Конгрессе, осуществляя всю необходимую помощь сенаторам и сотрудникам их аппарата, включая подготовку выступлений, текстов законопроектов и пр. Каждый конгрессмен дважды в месяц получает бюллетень организации «Ближневосточный отчет». В свою очередь, еще одна еврейская организации - Американо-израильский образовательный фонд напрямую спонсирует поездки конгрессменов в Израиль. Как упоминалось выше, еврейское лобби регулярно участвует в подготовке коллективных писем конгрессменов сотрудникам администрации.

Впрочем, в дискуссию вокруг американской политики на Ближнем Востоке вовлечены не только структуры этнического лобби. Значимую роль играют и организации идеологического характера, многие из которых создаются с целью лоббирования той или иной конкретной внешнеполитической инициативы. Безусловно, важной темой в контексте рассмотрения американских заинтересованных групп «ближневосточной» направленности и их деятельности после 11 сентября 2001 года, является лоббирование начала войны в Ираке. Одной из организаций, действовавших в этом ключе, был вы-

${ }^{4}$ Jimmy Carter. Palestine: Peace Not Apartheid, Simon \& Schuster, 2006 шеупомянутый Комитет за освобождение Ирака, созданный по инициативе Стивена Хэдли, в тот момент - заместителя Советника президента по вопросам национальной безопасности. Брюс Джексон, выбранный на роль руководителя Комитета благодаря успешной в прошлом деятельности, направленной на продвижение идеи о расширении НАТО, не был экспертом по вопросам ближневосточной политики. Интересно, что, по словам Джексона, в ответ на его вопрос о причинах будущей войны (разговор имел место в 2002 году), Хэдли ответил, что «президент пока что не решил, какими будут ее причины». ${ }^{5}$ В результате, главной задачей организации стало лоббирование войны, повод для которой еще не был выбран. Джексон обратился к крупным экспертам по Ираку и Ближнему Востоку, параллельно наладив отношения с Иракским национальным конгрессом во главе с лидером зарубежной оппозиции Саддаму Хусейну Ахмедом Чалаби.

Декларируемой целью Комитета было «установление мира в регионе, политических свобод и международной безопасности, посредством замены С.Хусейна на демократическое правительство». Джексон смог привлечь к работе Ньюта Гингрича, Джона Маккейна, Джо Либермана и ряд других крупных действующих и бывших политиков. Каждодневной рутиной занимался Рэнди Шуниман, бывший сотрудник аппарата сенатора Трента Лотта, близкий к ИНК. Комитет сразу же приступил к действиям по убеждению конгрессменов в необходимости начала военной операции.

Сам ИНК также выступал в качестве активной заинтересованной группы. Чалаби еще в 1990-е годы нанял вашингтонских лоббистов для поддержки своих действий. Однако расцвет его деятельности приходится на период после терактов 11 сентября. К этому времени Чалаби установил тесные отношения с ведущими республиканскими политиками, включая Джона Маккейна. Даже более интенсивными явились контакты ИНК с демократами. Именно благодаря президенту Клинтону и вице-президенту Гору ИНК получал многомиллионные гранты, выделявшиеся Конгрессом из бюджета США. Джо Либерман, также участвовавший в предвыборной гонке, ранее стал одним из инициаторов подписания группы конгрессменов открытого письма в поддержку освобождения Ирака, он также

${ }^{5}$ Roston A. The Man Who Pushed America to War: The Extraordinary Life, Adventures and Obsessions of Ahmad Chalabi. Nation Books, 2008. 400 p. Page 33 


\section{Политика и общество 4 (100) • 2013}

добивался принятия Акта об освобождении Ирака. Чалаби лично участвовал в слушаниях в Сенате и использовал свои связи для принятия Акта, который, с одной стороны, обеспечил ИНК государственную поддержку, с другой - в дальнейшем был использован Бушем-мл. в качестве одного из оправданий начала войны. В первой половине 2000-х гг. ИНК безусловно ориентировался на новую администрацию и неоконсерваторов, один из которых, Ричард Перл выступил связующим звеном между Чалаби и республиканцами, инициировавшими начало иракской войны.

Другая ключевая структура сторонников иракской кампании, Проект за Новый Американский Век, была создана идеологами неоконсервативного течения Уильямом Кристолом и Робертом Кэганом в 1997 году как некоммерческая организация, целью которой является продвижение глобального лидерства Соединенных Штатов. Организация активно пропагандирует идею глобального доминирования США и расширения американского присутствия в различных регионах мира.

Долгое время «Проект» призывал США выйти из договора ПРО, что, кстати, и было сделано в 2002 году. В сентябре 2002 года Проект обнародовал доклад на 90 страниц, под названием «Передел американской обороны: стратегии, силы и ресурсы для Нового Века» (Rebuilding America's Defences: Strategies, Forces, and Resources For A New Century) ${ }^{6}$, исходя из убеждения в том, «что Америка должна стараться сохранить и распространить свое глобальное лидерство путем установления преимущества американских военных сил».

Любопытным фактом является то обстоятельство, что после выборов 2000 года многие представители «Проекта за Новый Американский Век» были назначены на ведущие посты в администрации Джорджа Буша. Среди них заместитель Госсекретаря и, позднее, представитель США в ООН Джон Болтон, вице-президент США Дик Чейни, посол США в Ираке и Афганистане и представитель в ООН Залмай Халилзад, министр обороны Дональд Рамсфельд, замминистра обороны и президент Мирового Банка Пол Вулфовиц, а также другие известные неоконсерваторы.

«Проект за Новый Американский Век» обрел широкую, в каком-то смысле, даже скандальную известность в ходе процессов, предшествовавших кампании

${ }^{6}$ A Report of the Project for the New American Century, September 2000
2003 года. Известно, что в одном из документов организации прямо говорилось, что трансформация и увеличение американской мощи и влияния в краткосрочной перспективе реальны только в случае катастрофического события типа атаки в Перл-Харборе, аналогии с которой активно проводились после терактов 11 сентября 2001 года. Неудивительно, что Проект и его сотрудники выступали в поддержку начала войны и на всем ее протяжении добивались увеличения американского контингента в Ираке. В 2004 году сотрудники проекта добились опубликования открытого письма к конгрессменам с соответствующим требованием, подписанного как представителями консервативного лагеря, так и экспертами, близкими к демократам. Ранее, сразу после начала войны, Проект инициировал другое письмо к членам Конгресca, согласно которому, американские ВС должны в этой стороне, «столько, сколько потребуется». Письмо было поддержано не только республиканцами, но и несколькими видными демократами. Объединение консерваторов и либералов в борьбе за свержение Хусейна стало одним из важнейших достижений провоенного лобби.

В настоящий момент по примеру организаций, выступавших за войну в Ираке, в США действуют объединения, настаивающие на более жестких действиях в отношении Тегерана. Многие из них сформировались еще в 2000-е годы. Так, в Вашингтоне зарегистрирован Фонд иранской свободы, представителем которого выступает известный политтехнолог Джером Корси. С фондом взаимодействует Альянс за демократию в Иране, в руководство которого в основном входят иранцы и американцы иранского происхождения. В свою очередь, другая организация - Коалиция за демократию в Иране, создана в основном неоконсервативными деятелями, в том числе, бывшим сотрудником администрации Рейгана Майклом Ледином и бывшим исполнительным директоров AIPAC Морисом Эмитеем. В содружестве с ними действует и Фонд в защиту демократий.

Самой деятельной из перечисленных организаций можно считать Коалицию за демократию в Иране. Совместно с АIPAC Коалиция отстаивает идею введения санкций против Тегерана. Среди ее сторонников в Сенате стоит отметить республиканцев Сэма Браунбэка, Джона Кайла, Кристофера Кокса, Рика Санторума спонсоров ряд соответствующих резолюций.

Учитывая широкую дискуссию в СМИ и экспертных кругах относительно возможности прове- 
дения новых наступательных акций США за рубежом и наличия свежего опыта в лице кампании в Ливии, события прошлых лет демонстрируют характер влияния групп на настроения конгрессменов по данным вопросам.

Как мы видим, возрастание роли заинтересованных групп, ориентированных на ближневосточную политику происходило постепенно. Сегодня благодаря значимости данного фактора в американской политике и стремлению самых различных сил к вовлечению в процесс принятия внешнеполитических решений, самые разные группы приобрели значительное влияние в Конгрессе. Участие заинтересованных групп наблюдается при рассмотрении практически каждого значимого вопроса повестки дня, что делает их активной силой во всем процессе формирования американской политики. При этом, способность тех или иных организаций влиять на американский политический процесс, целиком и полностью зависит от их собственных вложений в увеличение своего влияния, гибкости и способность адаптироваться к меняющимся внутриполическим реалиям. В связи с неспособностью (вследствие незначительности диаспоры, широкого неприятия тех или иных политических идеологий и т.п.) или нежеланием отдельных субъектов вовлекаться в данный процесс, они оказываются исключенными из него, что приводит к общему дисбалансу в ходе принятия решений и формирования общественного мнения. Безусловно, подобное положение дел не способствует как стабилизации на Ближнем Востоке, так и изменению роли США в определении расстановки сил, о чем ранее говорил нынешний президент страны Б.Обама. В условиях негативного эффекта от событий «арабской весны» и увеличения кризисных тенденций в арабском мире и прилегающих странах, неспособность США нащупать новые подходы к урегулированию спорных ситуаций может деструктивно сказаться как на позициях крупнейшей мировой державы, так и на общем положении дел.

\section{Библиография:}

1. Зяблюк Н.Г. Власть, деньги, выборы: американский опыт. М.: ИСКРАН, 2012.272 с.

2. Зяблюк Н.Г. Общественные интересы в политическом процессе США. М.: ИСКРАН, 2004.124 с.
3. Зяблюк Н.Г. Практика лоббистской деятельности в США. М.: ИСКРАН, 1994. 42 с.

4. Павроз А. В. Группы интересов и лоббизм в политике. СПб.: Изд-во С.-Петербургского университета, 2006. 184 c.

5. Ambrosio T. Ethnic Identity Groups and U.S. Foreign Policy. Greenwood Publishing Group, 2002. 232 p.

6. Bard M. The Arab Lobby: The Invisible Alliance That Undermines America's Interests in the Middle East. HarperCollins, 2011 p. 432 p.

7. Davidson L. Foreign Policy, Inc.: Privatizing America's National Interest. University Press of Kentucky, 2009. 184 p.

8. Feingold H.L. Jewish Power in America: Myth and Reality. Transaction Publishers, 2011. 181 p.

9. Foxman A.H. The Deadliest Lies: The Israel Lobby and the Myth of Jewish Control. Palgrave Macmillan, 2009. $256 \mathrm{p}$.

10. Goldberg J.J. Foreign Policy and Ethnic Interest Groups: American and Canadian Jews Lobby for Israel. Greenwood Publishing Group, 1990. 197 p.

11. Goldberg J.J. Jewish power: inside the American Jewish establishment. Addison-Wesley, 1996. 422 p.

12. Marrar K. The Arab Lobby and US Foreign Policy. Taylor \& Francis, 2008. 272 p.

13. Mearsheimer J. J., Walt S.M. The Israel Lobby and U.S. Foreign Policy. Farrar, Straus and Giroux, 2008. $496 \mathrm{p}$.

14. Medoff R. Jewish Americans and Political Participation: A Reference Handbook. ABC-CLIO, 2002. $371 \mathrm{p}$.

15. Roston A. The Man Who Pushed America to War: The Extraordinary Life, Adventures and Obsessions of Ahmad Chalabi. Nation Books, 2008. 400 p.

\section{References (transliteration):}

1. Zyablyuk N.G. Vlast', den'gi, vybory: amerikanskiy opyt. M.: ISKRAN, 2012.272 s.

2. Zyablyuk N.G. Obshchestvennye interesy v politicheskom protsesse SShA. M.: ISKRAN, 2004. 124 s.

3. Zyablyuk N.G. Praktika lobbistskoy deyatel'nosti v SShA. M.: ISKRAN, 1994. 42 s.

4. Pavroz A. V. Gruppy interesov i lobbizm v politike. SPb.: Izd-vo S.-Peterburgskogo universiteta, 2006. $184 \mathrm{~s}$.

5. Ambrosio T. Ethnic Identity Groups and U.S. Foreign Policy. Greenwood Publishing Group, 2002. 232 p. 


\section{Политика и общество 4 (100) • 2013}

6. Bard M. The Arab Lobby: The Invisible Alliance That Undermines America's Interests in the Middle East. HarperCollins, 2011 p. 432 p.

7. Davidson L. Foreign Policy, Inc.: Privatizing America's National Interest. University Press of Kentucky, 2009. 184 p.

8. Feingold H.L. Jewish Power in America: Myth and Reality. Transaction Publishers, 2011. 181 p.

9. Foxman A.H. The Deadliest Lies: The Israel Lobby and the Myth of Jewish Control. Palgrave Macmillan, 2009. 256 p.

10. Goldberg J.J. Foreign Policy and Ethnic Interest Groups: American and Canadian Jews Lobby for Israel. Greenwood Publishing Group, 1990. 197 p.
11. Goldberg J.J. Jewish power: inside the American Jewish establishment. Addison-Wesley, 1996. 422 p.

12. Marrar K. The Arab Lobby and US Foreign Policy. Taylor \& Francis, 2008. 272 p.

13. Mearsheimer J. J., Walt S.M. The Israel Lobby and U.S. Foreign Policy. Farrar, Straus and Giroux, 2008. $496 \mathrm{p}$.

14. Medoff R. Jewish Americans and Political Participation: A Reference Handbook. ABC-CLIO, 2002. $371 \mathrm{p}$

15. Roston A. The Man Who Pushed America to War: The Extraordinary Life, Adventures and Obsessions of Ahmad Chalabi. Nation Books, 2008. 400 p. 